\title{
Self perception and quality of life of adolescents who had undergone open-heart surgery due to cyanotic congenital heart disease in their infancy
}

\author{
Cenk Eray Yıldız ${ }^{1}$, Gürkan Çetinn ${ }^{1}$, Oğuzhan Zahmacıoğlu ${ }^{2}$, Bülent Koca ${ }^{3}$, Selman Gökalp ${ }^{3}$, \\ Ayşe Güler Eroğlü ${ }^{3}$, Veysel Oktay ${ }^{4}$
}

1) Istanbul University Institute of Cardiology, Department of Cardiovascular Surgery, Istanbul, Turkey

2) Yeditepe University Medical Faculty, Department of Child and Adolescent Psychiatry, Istanbul, Turkey

3) Istanbul University Cerrahpaşa Medical Faculty, Division of Pediatric Cardiology, Istanbul, Turkey

${ }^{4)}$ Istanbul University Institute of Cardiology, Istanbul, Turkey

\section{Summary}

Aim: To assess the quality-of-life of the teenage patients who had undergone open heart surgery because of cyanotic heart disease during their infancy together with their parents and to compare their self-perception to that of the physically healthy control group.

Material and Method: This study includes 53 patients who had undergone operation for cyanotic congenital heart disease in İstanbul University, Institute of Cardiology between 1989 and 1994. The relatives and the patients were informed with a consent form approved by İstanbul University, Cerrahpaşa Medical Faculty, Clinical Studies, Ethics Commitee (Decree no. D-005, Date: 11-10-2009). Group 1 was the healthy control group (15 patients, median age: 19 years 8 months), Group 2 included patients with single ventricle who had undergone Fontan procedure (20 patients, median age: 19 years 6 months; 10 of them had tricuspid atresia, 5 of them had pulmonary atresia with intact ventricular septum, 3 of them had double inlet left ventricle, 1 of them had double outlet right ventricle, 1 of them had ventricular septal defect and pulmonary atresia), group 3 included patients who had undergone operation for congenital cyanotic heart disease (33 patients, median age: 19 years 2 months; 18 of them had transposition of the great arteries, 10 of them had tetralogy of Fallot, 2 of them had complete atrioventricular canal defect and pulmonary stenosis, 2 of them had double outlet right ventricle, 1 of them had pentalogy of Fallot). In this study, the quality of life and self perception inventories were used. The quality of life inventory was completed by patients, healthy adolescents and their parents seperately. The self perception inventory was completed only by the patients and healthy adolescents. The comparison of age and self perception scores between the groups was carried out with unidirectional analysis of variance (ANOVA) and the multicomparisons with LSD (Least Significant Difference). Since the quality of life variable did not have a normal distribution, the comparions were carried out with Kruskal-Wallis nonparametric ANOVA test and the multicomparisons were carried out with Dunn's test.

Results: There was not a significant difference between the groups in terms of age and sex. In the quality of life scale (QOLS), for the replies to related questions, a significant difference was determined between the groups. The replies of group 2 and 3 about quality of life of both the children and the parents were far more negative when compared to those of the control group. When the groups were compared via multiple comparison tests, there was no significant difference between group 2 and 3. The replies of the parents regarding their children's quality of life were statistically more negative than those of their children $(\mathrm{p}<0,001)$. Within the self perception scale, there were significant differences in terms of social acceptance, behaviours in relationships and general self perception ( $p=0,03, p=0,03$ and $p=0,01$; repectively) between group 1 and 3. The most significant difference that was detected between group 1 and 2 was about behaviours in relationships $(\mathrm{p}=0,04)$.

Conclusion: With the help of developing technology and surgical experience, many complex cyanotic heart diseases are treated successfully and most patients reach puberty. However the responses for quality of life and self perception paremeters of this group of patients are more negative than those of the control group. Therefore, these adolescents and especially their parents may need psychosocial support.

Keywords: Adult, congenital heart disease, cyanosis, quality of life, self-perception profile 


\section{Introduction}

Significant complications of congenital heart diseases which occur with a rate of 8-12 per 1000 live births include congestive heart failure, hypoxia and cyanosis. Cyanosis appears when reduced hemoglobin in cutaneous veins increases above $5 \mathrm{~g} / 100 \mathrm{~mL}$. Congenital heart diseases leading to cyanosis include transposition of the great arteries, Fallot tetralogy, total anomalous pulmonary venous return, tricuspid atresia, pulmonary atresia with intact ventricular septum, hypoplastic left heart syndrome, truncus arteriosus, single ventricle, double outlet right ventricle and atrial isomerisms. Early diagnosis of these complex heart anomalies and management in the neonatal period or in infancy by assistant and/or full correction operations have vital importance.

Low oxygen level in the blood and side effects of cardiopulmonary by pass affect many organs negatively including mainly the brain. ${ }^{(1,2)}$ While full correction operations are performed for many complex congenital heart anomalies, Fontan operation which is known as an assistant intervention is performed in patients with single ventricle. With Fontan operation systemic venous return is directed to the pulmonary system and single ventricle is provided to maintain systemic circulation. Patients who have undergone Fontan operation should be evaluated separately form other congenital heart diseases because of problems including metabolic and hormonal factors and low saturation rate.

The World Health Organization defines health as a state of complete physical, mental and social wellbeing. Studies for definition of complete well-being has introduced the concept of quality of life and quality of life has been briefly defined as an individual's perception of their position in life in the context of the culture and value system in which they live. ${ }^{(3,4)}$ In the end of the last century, health-related quality of life which emphasizes individual point of view gained importance in the evaluation of data related to health, clinical studies and results of new treatments. It was reported that interventions to improve quality of life in the early ages would be beneficial for prevention of or protection from problems of quality of life which would occur in the future and would guide the physicians in directing treatment. ${ }^{(5)}$ The term "health-related quality of life" which is defined as perception of the effects of a disease and its treatment on the patient by the patient shows variance according to the patient's individual characteristics. ${ }^{(6)}$

Our aim was to emphasize the physical and psychosocial functionalities of adolescents who had undergone open heart surgery because of congenital heart disease in infancy together with their parents, to determine the level of self perception and enlighten the subject of what could be done in case of negativities.

\section{Material and Method}

53 patients who were operated because of congenital cyanotic heart disease between 1989 and 1994 in İstanbul University Institute of Cardiology were included in the study. 15 individuals who had no complaints, whose physical examination was normal and who were healthy physically ( 8 males, 7 females; mean age 19 years 8 months) were included as the control group (group 1). 20 patients who had undergone Fontan operation (10 males, 10 females; mean age 19 years 6 months) constituted group 2 and 33 patients who had been operated because of other cyanotic heart diseases (20 males, 13 females; mean age: 19 years 2 months) constituted group 3 .

Assistant interventional methods and operations performed before Fontan operation in patients who had undergone Fontan operation and the ages at the time of these interventions; balloon atrial septostomy in two subjects [ 1 day old $^{(1)}, 2$ days old ${ }^{(1)}$, Glennshunt in 11 subjects [0-1 years old ${ }^{(6)}, 1-2$ years old ${ }^{(4)}, 2-3$ years old $^{(1)}$, Blalock-Taussig shunt in 5 subjects [4 months old $^{(1)}, 1-2$ years old ${ }^{(3)}, 2-3$ years old $\left.{ }^{(1)}\right]$, pulmonary band in 1 subject ( 1 month old).

Assistant interventional methods and operations performed in patients with other congenital cyanotic heart diseases and the ages at the time of these interventions; balloon atrial septostomy in 4 subjects $\left[1\right.$ day old ${ }^{(2)}$, 2 days old ${ }^{(2)}$ and Blalock-Taussig shunt in 7 subjects [0-1 months old ${ }^{(4)}, 2$ months old ${ }^{(2)}, 4$ months old $\left.{ }^{(1)}\right]$. While classical Fontane was performed in 5 of 20 patients who had single ventricle anomaly (right atriumpulmonary artery anastomosis), total cavapulmonary anastomosis was performed in 15 subjects. 7 of these were performed as intracardiac (lateral) tunnel and 8 were performed as extracardiac tunnel. Tube grafts were used in 3 patients and autologous pericardium was 
used in 5 patients for extracardiac tunnel. In 33 patients with other complex cardiac anomalies, complete correction operations (Senning, Jatene, Rastelli etc.) were performed according to the type of the disease. While the time of cardiopulmonary by pass was found to be $56,55 \pm 16,02$ minutes in group 2, it was found to be $83,88 \pm 33,64$ minutes in group 3 . There was a significant difference between the two patient groups in terms of cardiopulmonary by pass time $(\mathrm{t}=3,397$; degree of independence $($ d.i $)=51 ; p<0,001)$.

Patients were randomly selected during routine outpatient follow-up. Adolescent patients, physically healthy adolescents and their parents completed the Quality of Life Scale form seperately. The Self perception Scale form was completed only by the adolescent patients and physically healthy adolescents. Different question groups in both subjects were responded in 15 minutes. Approval was obtained from the İstanbul University Cerrahpaşa Medical Faculty Clinical Research Ethics Committe (decision number: D-500, Date: 1110-2009). The patients and relatives were informed with the informed consent form.

\section{Quality of life inventory}

For evaluation of quality of life the Quality of Life Inventory Adolescent form which was developed by Varni et al. ${ }^{(7)}$ in 1999 and which was examined afterwards in terms of validity and reliability for the Turkish language was used ${ }^{(8,9)}$. The inventory consists of four parts which question physical, emotional, social and academic functionality. The part of physical functionality contains 8 questions, the parts of emotional functionality, social functionality and academic functionality contain 5 questions each. These questions are directed to the children and their parents. For answers likert type answer scale with five options is used $(0=$ never, $1=$ rarely, $2=$ sometimes, $3=$ frequently, $4=$ always). In the part of physical functionality, score of the 8 items are summed and divided to 8 to obtain the total score of physical health.

Total scores are obtained for each area by summing of the scores of 5 items in each part including emotional functionality, social functionality and school-related problems which constitute psychosocial health and dividing to five which is the total number of items. ${ }^{(10)}$

\section{Self-perception profile for adolescents (SPPA)}

This is the form arranged for adolescents derived from the self-perception profile for children which was developed by Harter. ${ }^{(11)}$ In the English source of the self-perception profile for adolescents, alpha coefficient which expresses self-consistency ranges between 0,78 and 0,92 according to dimensions. ${ }^{(11)}$ In the study performed by Şahin and Güvenç ${ }^{(12)}$ in which SPPA was adapted to Turkish, alpha coefficient was found to be 0,88 and the reliability coefficient for test-retest which was performed in a sample group consisting of 130 individuals with intervals of three weeks was found to be 0,87 . In another pilot study performed in 197 highschool students in Turkey using SPPA, the reliability coefficients for test-retest (with an interval of 2 weeks) were found to range between 0,75 and 0,87 and for selfconsistency between 0,77 and $0,90 .^{(13)}$

Self-perception profile for adolescents is a likerttype scale consisting of 45 questions. It consists of 5 close questions mainly in 9 subscales. Two different sentences defining two different personalities are contained in the items. The person filling out the profile is asked to decide which one of the two groups he/she belongs to and to mark if this sentence is fully or partially appropriate for himself/herself. However, it should be kept in mind that psychological disorder is not meant when mentioning negativity, because there is no psychiatric disorder like "low self-perception syndrome". In answers given to self-perception scales, a score of 1 means not perceiving oneself valuable, a score of 2 means perceiving oneself partially valuable, a score of 3 means perceiving oneself valuable and a score of 4 means perceiving oneself very valuable. These subscales and what they measure are summarized below:

Academic sufficiency: This subscale measures the self-perception of children about academic success and how intelligent they perceive themselves. Social acceptance: This subscale measures to what degree the children are accepted, liked and loved by their peers.

Athletic sufficiency: This subscale measures the selfperception about sportive success and athletic sufficiency.

Physical appearance: This subscale measures how satisfied one is with his/her physical appearance and body. 
Job sufficiency: This subscale evaluates the ability of the person in his/her job, if he/she is always ready to perform part-time jobs and their belief in how well they perform their jobs.

Romantic attraction: These questions measure if the person is found attractive by the individuals he/she likes and if he/she can go out with people he/she likes.

Behaviour in relations: This subscale measures how satisfied the person is with his/her own behaviour and the self-perception how well he/she does what he/ she is expected to do or what is right.

Intimate friendship: This subscale measures the self-perception about the ability to institute intimate friendship where the person can share personal thoughts and secrets.

General self-value: This subscale measures how much the person loves himself/herself and how he/she is satisfied with his/her life. The person's judgements related to his/her values are evaluated. Even evaluation of this subscale alone is important.

\section{Statistical analysis}

In assessment of the data, SPSS (SPSS Inc., Chicago, IL, USA) 16.0 for Windows was used. The distribution of frequency of the groups by gender was assessed using chi-square test. In comparison of cardiopulomonary by pass times of the two patients groups who had undergone operation, student's $t$ test was used. In comparison of the scores of age and self-perception, singletail analysis of variance (ANOVA) was used. Multiple comparisons were performed using LSD (Least Significant Difference). Since the variable of quality of life did not have a normal distribution, comparisons were done using Kruskal-Wallis nonparametric ANOVA test and multiple comparisons were done using Dunn test. In all hypothesis tests, a $\mathrm{p}$ value of $<0,05$ was considered to be significant.

\section{Results}

No statistically significant difference was found between the groups in terms of age and gender $(p=0,56$ and $\mathrm{p}=0,73$, respectively). When statistical comparison of the answers to the Quality of Life Scale questions between the groups was done using Kruskal-Wallis non- parametric ANOVA test, a significant difference was observed in all questions both in the form for the child and the form for the parents (Table 2). In comparison of the groups using multiple comparison test of Dunn, a significant difference was observed between group 1 and group 2 and group 1 and group $3(\mathrm{p}<0,05)$. No significant difference was found between group 2 and 3 $(p>0,05)$. The approaches of the parents in the answers to questions about quality of life of their children were observed to be much more negative $(p<0,001)$.

In the answers of the adolescents to the questions about self-perception, no significant difference was found between the groups except for general self-perception $(\mathrm{p}=0,05)$ using single-tail variance analysis (Table 3). However, significant difference was observed especially between group 1 and group 3 in terms of social acceptance, behaviour in relations and general self value ( $p=0,03, p=0,03$ and $p=0,01$, respectively) using multiple comparison test LSD. The only significant difference between group 1 and group 2 was observed in behaviour in relations $(\mathrm{p}=0,04)$.

\section{Discussion}

Dysfunctionality observed in adolescents who had congenital heart disease and who had undergone open heart operation during infancy for this reason is an issue which should be emphasized. Although the patients tend to evaluate their own behaviour in a similar way to healthy adolescents, their parents and others evaluate the patients' quality of life negatively compared to the healthy population. The reason for this is the fact that families and especially mothers are emotionally pessimistic from the first day with the thought that their children have chronic heart disease and observe them differently in each stage of their lives. ${ }^{(14)}$ Recent neurodevelopmental studies on children with congenital heart disease have evaluated the problems which these patients and their families experience by assessing not only intellectual functions, but also psychosocial adaptation and quality of life. ${ }^{(14,22)}$

With the advance of surgical notion and experience in parallel to the technology in the last 30 years, the baby who undergoes increasing number of heart operations each year grows, starts school life and even reaches adolescence. ${ }^{(15)}$ In patients with complex heart 
anomalies, a need for improving quality of life in the ones who survive after operation has become prominent. ${ }^{(16,17)}$ All patients are exposed to psychological stress caused by having chronic cardiac disease for years. ${ }^{(18)}$ Although an increase in the diagnoses of attention deficit and hyperactivity disorder has been observed in school-age children with cardiac disease in many current studies, the thoughts of the teachers and parents are omitted especially in evaluation of academic success. ${ }^{(19,20)}$ The parents who observed each stage of their children were also included in our study and their answers revealed that they were more pessimistic about quality of life of their children with chronic disease. Therefore, the patients should be evaluated together with their parents as a whole.

Another significant point is the fact that published studies were focused on small patients groups or patients with a single cardiac problem. ${ }^{(21,22)}$ Because of the dynamic nature of growth during infancy and childhood the validity of prediction assessments obtained during this period is limited. ${ }^{(23)}$ Therefore, our study groups were consisted of adolescents who had just completed their childhood. Evaluation of neurodevelopmental outcome of children with congenital heart disease requires long-term follow-up during school period and afterwards to understand the significance and depth of the problems. This subject was addressed in long-term studies performed in 60 pediatric patients who had undergone arterial switch operation (Jatene) because of transposition of the great arteries in different periods by the same study group. ${ }^{(24,25)}$

In the study performed in patients with ages ranging between 7,9 and 14,3 years, deficiencies were observed in areas of attention, motor and cognitive functions, academic success, language, speech, neurological development and even social functionality in $55 \%$ of the patients.(24) This rate is two fold higher than the rate $(26 \%)$ found in evaluations performed at the mean age of 5,4 years. ${ }^{(25)}$

Children with congenital heart disease carry a risk of deficiency in personal and social ability required for a healthy daily life. Majnemar et al. ${ }^{(26)}$ reported that children with congenital heart disease aged 5 years old experienced problems in terms of personal care and social cognition using pediatric functional independence measurement. Shillingford et al. ${ }^{(27)}$ reported that $49 \%$ of the children received supportive academic service and $15 \%$ were placed in special classes in a study they performed in children with complex cardiac anomaly aged between 5 and 10 years old.

It should be kept in mind that evaluation of satisfaction of the person may change, since the desires of the child changes as the age gets older. On the other hand, the severity of congenital heart disease can not predict quality of life. For example, Ternestedt et al. ${ }^{(28)}$ showed that quality of life was better in patients with Tetralogy of Fallot compared to patients with atrial septal defect in a long-term follow-up study. It was concluded that the approach of social environment and family to the ill child can be efficient in the sociocultural frame.

In our study, when we examined quality of life in adolescents and in their parents in terms of physical health and psychosocial health (emotional and social functionality, school life), unfavorable findings were determined in all of them compared to physically healthy adolescents. This shows that these patients and their families lack quality of life.

When the answers to the questions of self-perception of adolescents who had undergone open heart surgery years ago were examined, unfavorable differences were observed especially between healthy adolescents and patients with cyanotic cardiac disease excluding single ventricle in terms of social acceptance, behaviour in relations and general self value. Although cardiac problems of patients with single ventricle who had undergone Fontan operation are more severe, more favorable self-perception compared to other cyanotic cardiac diseases may be attributed to the fact that cardiopulmonary by pass times of the patients with single ventricle were shorter compared to the patients with other cyanotic cardiac diseases. Most of the patients are conscious about their state. Because of some positive or negative comparisons in the society the relations of these patients with the environment are disrupted and they lose their self value. Therefore, we can list the contributions to daily life by measurement of quality of life and self-perception in these patient groups:

The possibility of evaluation of the patient by the team performing the clinical follow up not only by car- 
diologic measurements, but also in a biological, psychological and social integrity.

Perception of the patient that he/she is understood and considered important by the physicians and thus strengthening the sense of mutual trust.

Early detection of possible need for psychiatric assistance in accordance with unfavorable answers determined by the scales and referral to adolescent psychiatry for assistance.

One of the most notable findings of our study is the fact that the traces of anxiety in the psychological life of the parents caused by a vital health problem experienced by children during the early period of their lives persist even years have passed. According to this result, the family which is the first circle of environmental factors should be included in the process of medical follow-up. In addition, the fact that the parents reported more unfavorable answers compared to the adolescents on anxiety about life is such a significant and interest- ing subject which can not to be fictionalized and which should be examined in detail in an independent study. The psychological therapy of these patients should be planned in the context of the family.

On the first step, supportive groups can be formed by bringing families together under guidance of experts on the subject. Family therapy should be performed in patients who need further support. As a result of the data we obtained in our study, it is clear that pediatric and adolescence psychiatrists should play an active role in the follow-up of the adolescents in the patient group, because low scores of self-perception and quality of life may be signs of significant psychiatric disorders including depression and anxiety disorder. The collobaration which will be instituted between the clinics in this context is vital in terms of physical and psychological health of the adolescent. We hope that these data we obtained will be a step for more detailed studies which will be performed on the subject in the future. 


\section{References}

1. Nadas AS, Feyler DC. Hyopoxemia. In: JF Kean, JE Lock, DC Fyler, (eds). Pediatric cardiology. 2nd ed. Philadelphia, Pennsilvania: Saunders Elsevier, 2006: 97-101.

2. Barlow A, Pawade A, Wilkinson JL, Anderson RH. Cardiac anatomy in patients undergoing the Fontan procedure. Ann Thorac Surg 1995; 60:1324-30.

3. Saxena S, Orley J. Quality of life assessment. The World Health Organization perspective. Eur Psychiatry 1997; 12: 263-6.

4. Eser SY, Fidaner H, Elbi H, Fidaner C, Elbi H, Goker E. Yaşam kalitesinin olculmesi, WHOQOL-100 ve WHOQOL-BREF. Psikiyatri Psikoloji Psikofarmakoloji (3P) Dergisi 1999; 7: 5-13.

5. Eiser C, Morse R. A review of measures of quality of life for children with chronic illness. Arch Dis Child 2001; 84: 205-11.

6. Eiser C. Childrens quality of life measures. Arch Dis Child 1997; 77:3504.

7. Varni JW, Rode AC. The Peds QLTM : The measurement model for the Pediatric Quality of Life Inventory. Medical Care 1999;37: 126-39.

8. Uneri OS, Agaoglu B, Coskun A, Memik NC. Validity and reliability of Pediatric Quality of Life Inventory for 2- to 4-year-old and 5- to 7-year old Turkish children. Qual Life Res 2008; 17: 307-15.

9. Memik NC, Ağaoğlu B, Coşkun A, Uneri OS, Karakaya I. Cocuklar icin yaşam kalitesi olceğinin 13-18 yaş ergen formunun gecerlik ve guvenilirliği. Turk Psikiyatri Dergisi 2007; 18: 353-63.

10. Varni JW, Kurtin PS. Peds QLTM 4.0: Reliability and validity of the Pediatric Quality of Life Inventory version 4.0 generic core scales in healthy and patient populations. Medical Care 2001; 39: 800-12.

11. Harter S. Manuel for the self-perception profile for adolescents, Denver: University of Denver, 1988

12. Şahin D, Guvenc GB. Ergenlerde aile algısı ve benlik algısı. Turk Psikoloji Dergisi 1996; 11: 22-32.

13. Așcı FH, Gokmen H, Tiryaki G, Așci A. Self-concept and body image of Turkish high school male athletes and non-athletes. Adolescence 1997; 32: 959-68.

14. Bellinger DC, Newburger JW. Neuropsychological, psychosocial, and quality-of-life outcomes in children and adolescents with congenital heart disease. Prog Pediatr Cardiol 2010; 29: 87-92.

15. Welke KF, Ungerleider RM. Current assessment of mortality rates in congenital cardiac surgery. Ann Thorac Surg 2006; 82: 164-70.
16. Wu FM, Ukomadu C, Odze D, Mayer MG. Liver disease in the patients with Fontan circulation. Congenit Heart Dis 2011; 6: 190-201.

17. Koutlas TC, Gaynor JW, Nicolson SC, Steven JM, Wernovsky G, Spray TL. Modified ultrafiltration reduces postoperative morbidity after cavopulmonary connection. Ann Thorac Surg 1997; 64: 37-42.

18. Gentles TL, Gauvreau K, Mayer JE, et al. Functional outcome after the Fontan operation: factors influencing late morbidity. J Thorac Cardiovasc Surg 1997; 114: 392-403.

19. Hsia TY, Gruber PJ. Factors influencing neurologic outcome after neonatal cardiopulmonary bypass: what we can and cannot control. Ann Thorac Surg 2006; 81: 2381-8.

20. Hovels-Gurich H, Konrad K, Herpertz-Dahlmann B, Messmer BJ, Seghaye MC. Attentional dysfunction in children after corrective cardiac surgery in infancy. Ann Thorac Surg 2007; 83: 1425-30.

21. Mahle WT, Clancy RR, Moss EM, Gerdes M, Jobes DR, Wernovsky G Neurodevelopmental outcome and lifestyle assessment in schoolaged and adolescent children with hypoplastic left heart syndrome. Pediatrics 2000; 105: 1082-9.

22. Kirshbom PM, Flynn TB, Clancy RR, et al. Late neurodevelopmental outcome after repair of total anomalous pulmonary venous connection.J Thorac Cardiovasc Surg 2005; 129: 1091-7.

23. Bellinger DC. Neurobehavioral assessment in studies of exposures to neurotoxicants. Int Rev Res Mental Retard 2006; 30: 263-98.

24. Hovels-Gurich HH, Seghaye MC, Schnitker R, et al. Long-term neurodevelopmental outcomes in school-aged children after neonatal arterial switch operation. J Thorac Cardiovasc Surg 2002; 124: 448-58.

25. Hovels-Gurich H, Messmer BJ, von Bernuth G. Cognitive and motor development in preschool and school-aged children after neonatal switch operation. J Thorac Cardiovasc Surg 1997; 114: 578-85.

26. Majnemer A, Limperopoulos C, Rohlicek C, Rosenblatt B, Tchervenkov C. Developmental and functional outcomes at school entry in children with congenital heart defects. J Pediatr 2008; 153: 55-60.

27. Shillingford AJ, Glanzman MM, Ittenbach RF, Clancy RR, Gaynor JW, Wernovsky G. Inattention, hyperactivity, and school performance in a population of school-age children with complex congenital heart disease. Pediatrics 2008; 121: 759-67.

28. Ternestedt BM, Wall K, Riesenfeld T, Grith I, Schollin J. Quality of life 20 and 30 years after surgery in patients operated on for tetralogy of Fallot and for atrial septal defect. Pediatr Cardiol 2001; 22: 128-32.

Received: 11/07/2012

Accepted: 25/11/2012

Published: 23/02/2013

Disclosure and conflicts of interest:

Conflicts of interest were not reported.

\section{Corresponding author:}

Dr. Cenk Eray Yildız

Mail: ceyildiz@hotmail.com 